\title{
Exacerbations and health care resource utilization in patients with airflow limitation diseases attending a primary care setting: the PUMA study
}

This article was published in the following Dove Press journal:

International Journal of COPD

7 December 2016

Number of times this article has been viewed

\author{
Maria Montes de Oca' \\ Carlos Aguirre ${ }^{2}$ \\ Maria Victorina Lopez \\ Varela ${ }^{3}$ \\ Maria E Laucho-Contreras' \\ Alejandro Casas ${ }^{2}$ \\ Filip Surmont ${ }^{4}$ \\ 'Service of Pneumology, Hospital \\ Universitario de Caracas, Facultad \\ de Medicina, Universidad Central \\ de Venezuela, Caracas, Venezuela; \\ ${ }^{2}$ Colombian Pneumological \\ Foundation, Bogotá, Colombia; \\ ${ }^{3}$ Universidad de la República, Facultad \\ de Medicina, Hospital Maciel, \\ Montevideo, Uruguay; ${ }^{4}$ Medical Affairs, \\ AstraZeneca Latin America, Coral \\ Gables, FL, USA
}

Correspondence: Maria Montes de Oca Hospital Universitario de Caracas,

Facultad de Medicina, Los Chaguaramos, 1030, Universidad Central de Venezuela, Caracas, Venezuela

Tel/fax +58 2I 25526088

Email montesdeoca.maria@gmail.com
Background: COPD, asthma, and asthma-COPD overlap increase health care resource consumption, predominantly because of hospitalization for exacerbations and also increased visits to general practitioners (GPs) or specialists. Little information is available regarding this in the primary care setting.

Objectives: To describe the prevalence and number of GP and specialist visits for any cause or due to exacerbations in patients with COPD, asthma, and asthma-COPD overlap.

Methods: COPD was defined as post-bronchodilator forced expiratory volume in 1 second/ forced vital capacity $\left(\mathrm{FEV}_{\mathrm{l}} / \mathrm{FVC}\right)$ ratio $<0.70$; asthma was defined as prior medical diagnosis, wheezing in the last 12 months, or wheezing plus reversibility (post-bronchodilator $\mathrm{FEV}_{1}$ or FVC increase $\geq 200 \mathrm{~mL}$ and $\geq 12 \%$ ); asthma-COPD overlap was defined as post-bronchodilator $\mathrm{FEV}_{1} / \mathrm{FVC}<0.70$ plus prior asthma diagnosis. Health care utilization was evaluated as GP and/or specialist visits in the previous year.

Results: Among the 1,743 individuals who completed the questionnaire, 1,540 performed acceptable spirometry. COPD patients had a higher prevalence of any medical visits to any physician versus those without COPD ( $37.2 \%$ vs $21.8 \%$, respectively) and exacerbations doubled the number of visits. The prevalence of any medical visits to any physician was also higher in asthma patients versus those without asthma (wheezing: $47.2 \%$ vs $22.7 \%$; medical diagnosis: $54.6 \%$ vs $21.6 \%$; wheezing plus reversibility: $46.2 \%$ vs $23.8 \%$, respectively). Asthma patients with exacerbations had twice the number of visits versus those without an exacerbation. The number of visits was higher (2.8 times) in asthma-COPD overlap, asthma (1.9 times), or COPD (1.4 times) patients versus those without these respiratory diseases; the number of visits due to exacerbation was also higher (4.9 times) in asthma-COPD overlap, asthma (3.5 times), and COPD (3.8 times) patients.

Conclusion: COPD, asthma, and asthma-COPD overlap increase the prevalence of medical visits and, therefore, health care resource utilization. Attempts to reduce health care resource use in these patients require interventions aimed at preventing exacerbations.

Keywords: COPD, asthma, asthma-COPD overlap, exacerbation, health care resource utilization, primary care, PUMA

\section{Introduction}

With the increasing age of the global population, chronic respiratory diseases are becoming a major cause of death and disability. COPD and asthma are two major causes of morbidity and mortality worldwide. ${ }^{1-9}$ These conditions impair quality of life, generate permanent work disabilities, and have considerable direct and indirect health care system costs..$^{9-17}$ 
A COPD exacerbation is the most common condition that requires hospital admission with the hospitalization contributing substantially to the related economic impact. ${ }^{15,18-21}$ Recently, the Continuing to Confront COPD International Patient Survey estimated the prevalence, economic impact, and burden of COPD across 12 countries and found that the annual social costs per patient range from US $\$ 1,721$ (Russia) to US $\$ 30,826$ (USA). ${ }^{17}$ The largest direct cost in 5 of the 12 countries was attributed to hospitalizations. The other health care resources with greater contributions to direct costs in the treatment of COPD were home oxygen therapy, general practitioners (GPs) or specialist visits, and medication costs. ${ }^{17}$ As anticipated, the costs for patients with breathlessness, worse symptoms, and a greater number of comorbidities were higher. ${ }^{17}$

Other studies have also shown that a significant proportion of health care resource consumption in the treatment of COPD results from hospitalizations due to exacerbations and less than $20 \%$ results from outpatient care (excluding medication) and diagnostic tests. ${ }^{10,22}$ Therefore, prevention of COPD exacerbations is considered the most important target to reduce costs. ${ }^{15}$

However, the results of a systematic review reported physician visits or office-based visits to be the largest expense of asthma-related direct costs, accounting for $55 \%-58 \%$ of direct costs. ${ }^{12} \mathrm{~A}$ separate study has shown that in asthma, similar to that of COPD, the presence of exacerbations has also been associated with higher total and asthma-related health care costs, and patients with moderate/severe persistent asthma who experienced exacerbations had higher health care costs. ${ }^{23}$

Little information is available from the primary care setting regarding health care resource use, prevalence of GP or specialist visits, and attendance of outpatients due to exacerbations for patients with either COPD, asthma, or asthma-COPD overlap. Recently, the Prevalence St $\underline{U}$ dy and Regular Practice, Diagnosis and TreatMent, Among General Practitioners in Populations at Risk of COPD in Latin America (PUMA) study, conducted in the primary care setting, evaluated the prevalence of airflow limitation in a population at risk for COPD. ${ }^{24,25}$ This study provides a good opportunity to assess different aspects of airway limitation diseases in a large international primary care sample from Latin America. Therefore, the aims of this study were to 1) assess the frequency of any medical doctor visit in the past year, according to several variables in the PUMA population and 2) describe the prevalence and frequency of attendance to GPs and specialists for general causes and those due to exacerbations of either COPD, asthma, or asthmaCOPD overlap.

\section{Methods}

The PUMA study was conducted in four Latin American countries: Argentina, Colombia, Venezuela, and Uruguay. Complete details of the methodology have been published previously. ${ }^{24-27}$ In summary, this was a multicenter, multinational, cross-sectional, and non-interventional study. Participating sites were selected according to local feasibility based on a previous local availability database of potential principal investigators (not randomized) and included primary care centers (family doctors, GPs, etc.) with no direct connection with respiratory medicine specialists. These sites were selected to reflect the reality of national primary care practice in terms of geographical distribution and health care sector. The ethics committees for each site involved in the study (Comité de Ética Independiente CIAD Morón, Buenos Aires, Argentina; Comité de Bioética Iniciativa y Reflexión Bioética, Buenos Aires, Argentina; Comité de Ética Dirección Nacional de Sanidad de las Fuerzas Armadas, Dirección Técnica, Montevideo, Uruguay; Centro Nacional Biotica, Caracas, Venezuela; and Comité de Ética en Investigación de la Fundación Neumológica, Colombiana, Bogotá, Colombia) approved the protocol and all participants provided written informed consent.

At-risk patients were included in the study if they were $\geq 40$ years of age, current or ex-smokers ( $\geq 10$ packyears, $\geq 50$ pipes/year, or $\geq 50$ cigars/year), and/or exposed to biomass smoke (wood or coal for cooking and heating; exposure $\geq 100$ hours/year).

Participants completed a modified version of the PLATINO study questionnaire ${ }^{1}$ for information on factors associated with COPD. Data on self-reported exacerbations and hospitalization due to an exacerbation were also obtained. Spirometry was performed using the Easy One spirometer (NDD Medical Technologies, Zurich, Switzerland). Spirometry tests were performed at baseline and after the inhalation of $400 \mu \mathrm{g}$ salbutamol, according to the American Thoracic Society criteria of acceptability and reproducibility.

The definitions of COPD, asthma, and asthma-COPD overlap used were

1. COPD: A ratio of post-bronchodilator forced expiratory volume in 1 second/forced vital capacity $\left(\mathrm{FEV}_{1} / \mathrm{FVC}\right)$ ratio $<0.70$ (Global Initiative for Chronic Obstructive Lung Disease [GOLD] definition or fixed ratio). ${ }^{28}$

2. Asthma: Three definitions were used: A) medical diagnosis of asthma (self-reported prior medical diagnosis of asthma), B) the presence of wheezing in the last 12 months, and C) the presence of wheezing in the last 12 months plus reversibility (post-bronchodilator increase in $\mathrm{FEV}_{1}$ or $\mathrm{FVC}$ of $200 \mathrm{~mL}$ and $12 \%$ ). 
3. Asthma-COPD overlap: A combination of the two disease definitions: a ratio of post-bronchodilator $\mathrm{FEV}_{1} /$ FVC $<0.70$ and prior medical diagnosis of asthma (selfreported prior medical diagnosis of asthma).

For the purpose of this study, the following dependent and independent variables were assessed:

Dependent variables: The use of health care resources and exacerbation history in patients with COPD, asthma, and asthma-COPD overlap. Health care utilization was evaluated as visiting a GP and/or specialist in the past year. Exacerbations were considered as any worsening of respiratory symptoms that was beyond normal day-to-day variations and led to a change in medication and/or any hospitalization (due to any exacerbation) in the past year.

Independent variables: Factors evaluated as being possibly associated with health care resource use were gender, age, skin color, schooling, pack-years smoked, modified Medical Research Council (mMRC) dyspnea scale, cough, phlegm, biomass exposure, exacerbation in the past year, asthma, and COPD.

\section{Statistical analysis}

Descriptive statistics with absolute $(\mathrm{N})$ and relative (\%) frequencies were used. In the bivariate analysis, chi-square tests were used for categorical exposures (independent variables) and outcomes (dependent variables). For comparisons among numerical variables and outcomes, analysis of variance and Student's $t$-tests were used. For the figures presented, only descriptive analyses were performed. A $P$-value of $5 \%$ was considered statistically significant. All analyses were performed using Stata software, release 13 (StataCorp, College Station, TX, USA).

\section{Results}

Participation rates in the PUMA study have been published elsewhere. ${ }^{24-27}$ Among the 1,743 patients who completed interviews, 1,540 had acceptable spirometry values. Only 203 of the 1,743 subjects who completed interviews did not have acceptable spirometry values (11.6\%).

Table 1 shows the sample distribution and prevalence of any medical visit in the past 12 months according to selected variables. The prevalence of any medical visit was higher in females, those patients of younger age (40-49 years) and less education, greater exposure to biomass smoke ( $\geq 10$ years), presence of respiratory symptoms (dyspnea, cough, phlegm), history of exacerbations in the last year, and asthma (defined by reversibility plus wheezing) or COPD (post-bronchodilator $\mathrm{FEV}_{1} / \mathrm{FVC}<0.70$ ). In addition, visits to the doctor in the last 12 months progressively increased as
Table I Total sample distribution and prevalence of any medical visit in the past 12 months

\begin{tabular}{|c|c|c|}
\hline Variables & $\mathbf{N}(\%)$ & $\begin{array}{l}\text { Doctor visit in the } \\
\text { past } 12 \text { months (\%) }\end{array}$ \\
\hline Gender & & $P=0.006$ \\
\hline Female & $876(50.3)$ & 29.7 \\
\hline Male & $867(49.7)$ & 23.9 \\
\hline Age (complete years) & & $P=0.030$ \\
\hline $40-49$ & $328(18.9)$ & 26.3 \\
\hline $50-59$ & $589(33.8)$ & 23.3 \\
\hline$\geq 60$ & $826(47.3)$ & 19.5 \\
\hline Skin color & & $P=0.321$ \\
\hline White & $882(50.9)$ & 25.7 \\
\hline Non-white & $851(49.1)$ & 27.9 \\
\hline $\begin{array}{l}\text { Education (complete years of } \\
\text { formal education) }\end{array}$ & & $P=0.0234$ \\
\hline $0-8$ & $892(51.2)$ & 28.0 \\
\hline$\geq 9$ & $851(48.8)$ & 25.5 \\
\hline Pack-years smoked & & $P=0.075$ \\
\hline$<20$ & $585(34.6)$ & 29.9 \\
\hline $20-30$ & $366(21.6)$ & 23.2 \\
\hline$>30$ & $740(43.8)$ & 26.8 \\
\hline mMRC dyspnea scale & & $P<0.00$ I \\
\hline No & $860(53.2)$ & 19.9 \\
\hline 1 & $315(19.5)$ & 22.5 \\
\hline 2 & $204(12.6)$ & 34.3 \\
\hline 3 & $188(11.6)$ & 43.1 \\
\hline 4 & $49(3.0)$ & 61.2 \\
\hline Cough & & $P<0.00$ I \\
\hline No & I, I 72 (67.2) & 22.3 \\
\hline Yes & $571(32.8)$ & 36.1 \\
\hline Phlegm & & $P<0.001$ \\
\hline No & I,220 (70.0) & 23.5 \\
\hline Yes & $523(30.0)$ & 34.4 \\
\hline Exposure to biomass $\geq 10$ years & & $P=0.012$ \\
\hline No & $1,160(66.6)$ & 24.9 \\
\hline Yes & $582(33.4)$ & 30.6 \\
\hline Exacerbation in the past year & & $P<0.00$ I \\
\hline No & $1,619(92.9)$ & 22.4 \\
\hline Yes & $123(7.1)$ & 84.6 \\
\hline Asthma (reversibility plus wheezing) & & $P<0.001$ \\
\hline \multicolumn{3}{|l|}{ and COPD (post-bronchodilator } \\
\hline \multicolumn{3}{|l|}{$\left.\mathrm{FEV}_{1} / \mathrm{FVC}<0.70\right)$} \\
\hline None & I I 8 (77.I) & 21.2 \\
\hline Only asthma & $43(2.8)$ & 48.8 \\
\hline Only COPD & $274(17.8)$ & 37.6 \\
\hline Both asthma and COPD & $35(2.3)$ & 45.7 \\
\hline GOLD stage & & $P<0.00$ I \\
\hline 0 & $|, 23|(79.9)$ & 22.2 \\
\hline I & $53(3.4)$ & 28.3 \\
\hline 2 & $169(11.0)$ & 32.0 \\
\hline $3-4$ & $87(5.7)$ & 57.5 \\
\hline
\end{tabular}

Abbreviations: $\mathrm{FEV}_{1}$, forced expiratory volume in I second; FVC, forced vital capacity; mMRC, modified Medical Research Council; GOLD, Global Initiative for Chronic Obstructive Lung Disease.

the severity of dyspnea (mMRC 1-4) and airway obstruction (GOLD stages 1-4) worsened.

Table 2 shows the characteristics of subjects with COPD, asthma, and asthma-COPD overlap according to the 
Table 2 Asthma-COPD overlap

\begin{tabular}{|c|c|c|c|c|}
\hline Variables & $\begin{array}{l}\text { Asthma } \\
(\mathrm{N}=149)\end{array}$ & $\begin{array}{l}\text { COPD } \\
(\mathrm{N}=227)\end{array}$ & $\begin{array}{l}\text { Asthma-COPD overlap } \\
(\mathbf{N}=\mathbf{8 2})\end{array}$ & $P$-value \\
\hline Age, years, mean (SD) & $56.3(9.7)$ & $67.8(9.0)$ & $65.0(9.8)$ & $<0.001$ \\
\hline Gender, male, n (\%) & $43(28.9)$ & $134(59.0)$ & $39(47.6)$ & $<0.001$ \\
\hline $\mathrm{BMI}, \mathrm{kg} / \mathrm{m}^{2}$, mean $(\mathrm{SD})$ & $30.0(5.5)$ & $26.3(5.8)$ & $26.4(6.1)$ & $<0.001$ \\
\hline Smoking, pack-years, mean (SD) & $26.8(21.6)$ & $48.3(30.2)$ & $35.0(27.4)$ & $<0.001$ \\
\hline \multicolumn{5}{|l|}{ Respiratory symptoms present, $\mathrm{n}(\%)$} \\
\hline Cough & $56(37.6)$ & $95(41.9)$ & $40(48.8)$ & $<0.001$ \\
\hline Phlegm & $40(26.9)$ & $100(44.1)$ & $39(47.6)$ & $<0.001$ \\
\hline Wheezing & $40(26.9)$ & $48(21.2)$ & $26(3 \mid .7)$ & $<0.00 \mathrm{I}$ \\
\hline Dyspnea & $83(61.0)$ & $126(59.4)$ & $56(75.7)$ & $<0.001$ \\
\hline Comorbidity score, mean (SD) & $1.2(1.0)$ & $1.2(0.9)$ & I.I (I.0) & 0.013 \\
\hline Any exacerbation within the past year, $\mathrm{n}(\%)$ (yes) & $23(15.4)$ & $19(8.4)$ & $14(17.1)$ & $<0.001$ \\
\hline
\end{tabular}

Abbreviations: BMI, body mass index; $\mathrm{FEV}_{\text {, }}$, forced expiratory volume in I second; FVC, forced vital capacity; SD, standard deviation.

definition of COPD (post-bronchodilator $\mathrm{FEV}_{1} / \mathrm{FVC}<0.70$ ) and asthma (asthma medical diagnosis). The number of comorbidities was lower in the asthma-COPD overlap. This group also had the highest percentage of respiratory symptoms and any exacerbation within the past year. Subjects in the asthma group were younger, predominantly female, smoked less, and had the highest body mass index.

The prevalence of medical visits (to GP/family doctor, specialist, or any) in the last year for general causes and due to an exacerbation is shown in Figure 1. Approximately, onequarter of the subjects visited a doctor in the last year and nearly $80 \%$ of those had an exacerbation; only $8.5 \%$ visited a specialist with $28 \%$ of these patients having an exacerbation. Patients who had exacerbations attended an emergency clinic/specialist while those without any exacerbations did not attend. The mean number of medical visits per year was one among those without exacerbations compared with 3.4 for those who had exacerbations; the mean number of visits per year to a specialist was the same (mean of 0.5) among those who had exacerbations.

The prevalence of medical visits (to GP/family doctor, specialist, or any physician) due to any cause and exacerbation in the last year for COPD is shown in Figure 2. COPD patients with post-bronchodilator $\mathrm{FEV}_{1} / \mathrm{FVC}<0.70$ had a higher prevalence of medical visits compared with those without COPD. The presence of exacerbations doubled the number of medical visits in the last year in the COPD patients using both criteria. GPs or family doctors were visited twice as frequently as specialists (Figure 2).

Figure 3 shows the prevalence of medical visits (to GP/ family doctor, specialist, or any physician) due to any cause and exacerbation in the last year in asthma using different criteria. Independent of the criteria used to define asthma (only wheezing, prior medical diagnosis, or wheezing plus

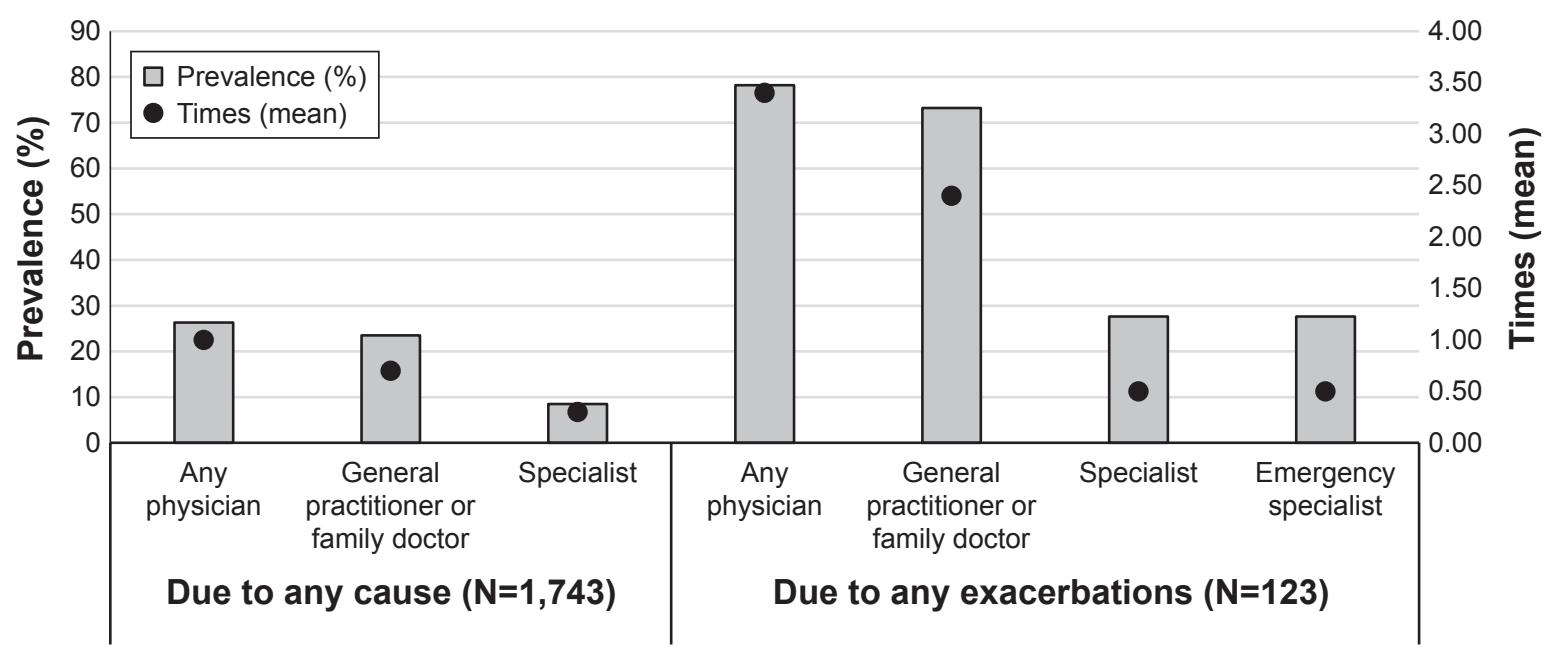

Doctor visit in the past 12 months

Figure I Prevalence of medical visits (to general practitioner/family doctor, specialist, or any physician) due to any cause or exacerbation in the last year. 


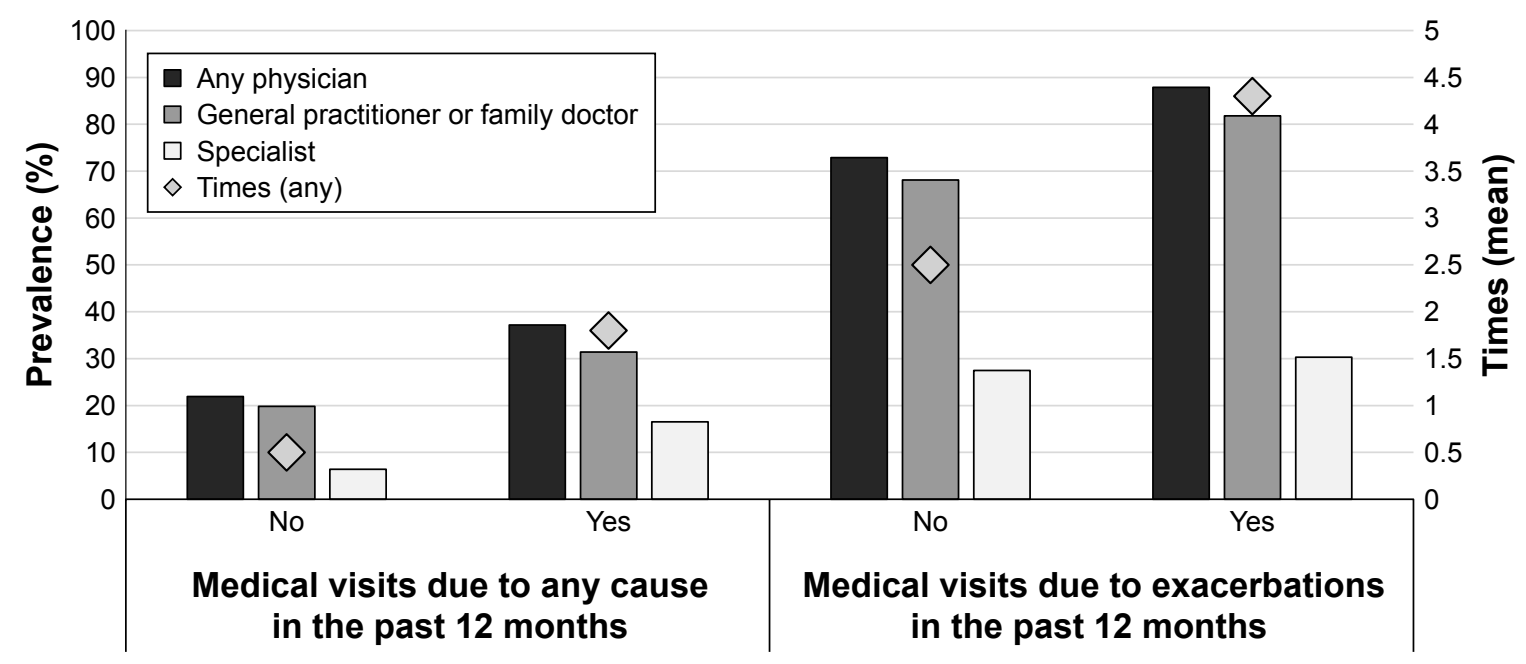

Figure 2 Prevalence of medical visits (to general practitioner/family doctor, specialist, or any physician) due to any cause or exacerbation in the last year for COPD (postbronchodilator $\mathrm{FEV}_{1} / \mathrm{FVC}<0.70$ ).

Abbreviations: $\mathrm{FEV}_{1}$, forced expiratory volume in I second; FVC, forced vital capacity.

reversibility), patients with asthma visited the doctor more frequently than those without asthma. As was observed in patients with COPD, asthma patients (independent of the definition used) experiencing an exacerbation had more number of medical visits in the last year (twice the number) than those without an exacerbation.

The prevalence of medical visits (to GP/family doctor, specialist, or any physician) due to any cause and exacerbation in the last year in patients with asthma-COPD overlap (post-bronchodilator $\mathrm{FEV}_{1} / \mathrm{FVC}<0.70$ plus asthma as prior medical diagnosis), those with only COPD (post-bronchodilator $\mathrm{FEV}_{1} / \mathrm{FVC}<0.70$ ), only asthma (prior medical diagnosis), and those without these conditions is shown in Figure 4. Visit to any doctor for general causes or due to an exacerbation was higher in patients with only asthma, only COPD, and asthma-COPD overlap compared with those without these conditions. Patients with asthmaCOPD overlap and exacerbations visited a doctor twice as frequently than those without exacerbations; the prevalence of specialist attendance was $35.7 \%$ among those patients with asthma-COPD overlap and exacerbations compared with $29.3 \%$ among those without exacerbations (Figure 4 ). The number of visits to any doctor in the last year was 2.8 times higher in patients with asthma-COPD overlap than in those

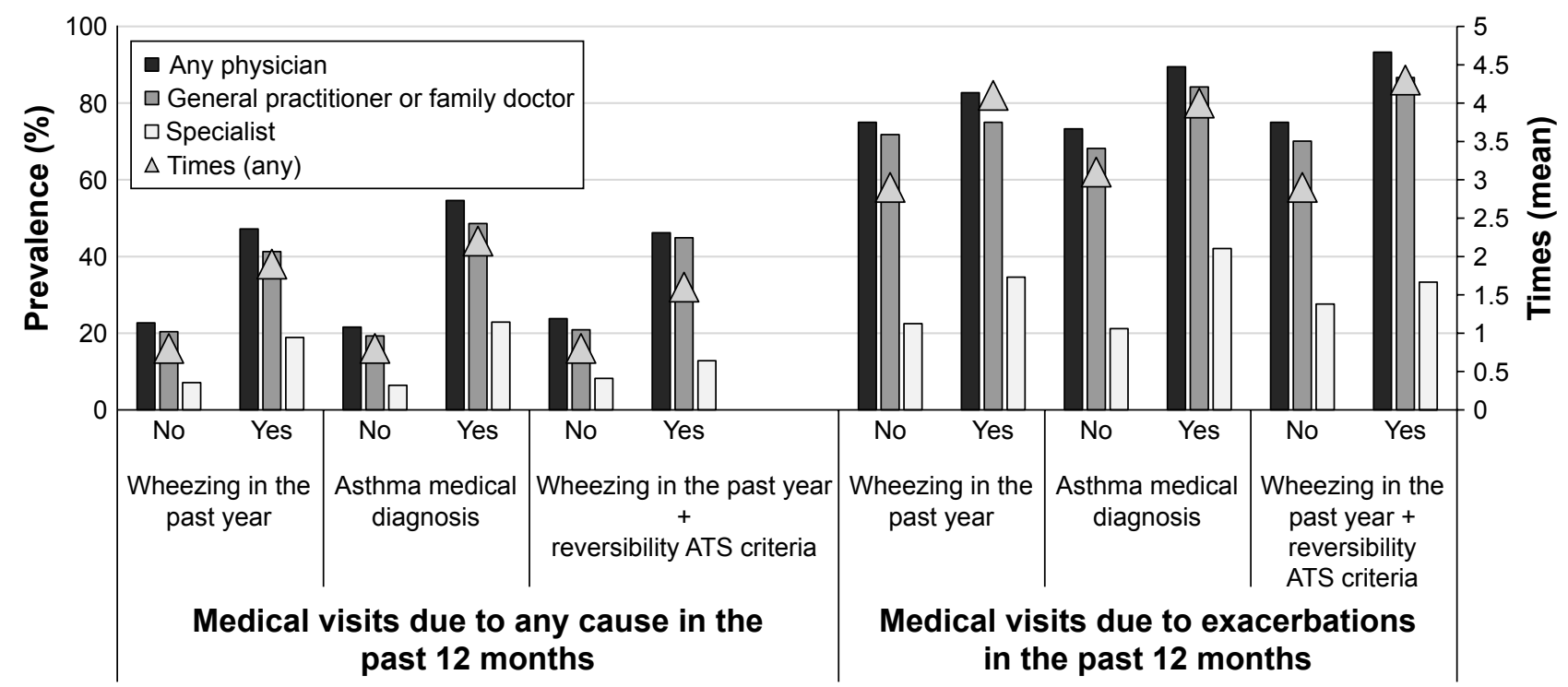

Figure 3 Prevalence of medical visits (to general practitioner/family doctor, specialist, or any physician) due to any cause or exacerbation in the last year for asthma using different criteria.

Abbreviation: ATS, American Thoracic Society. 


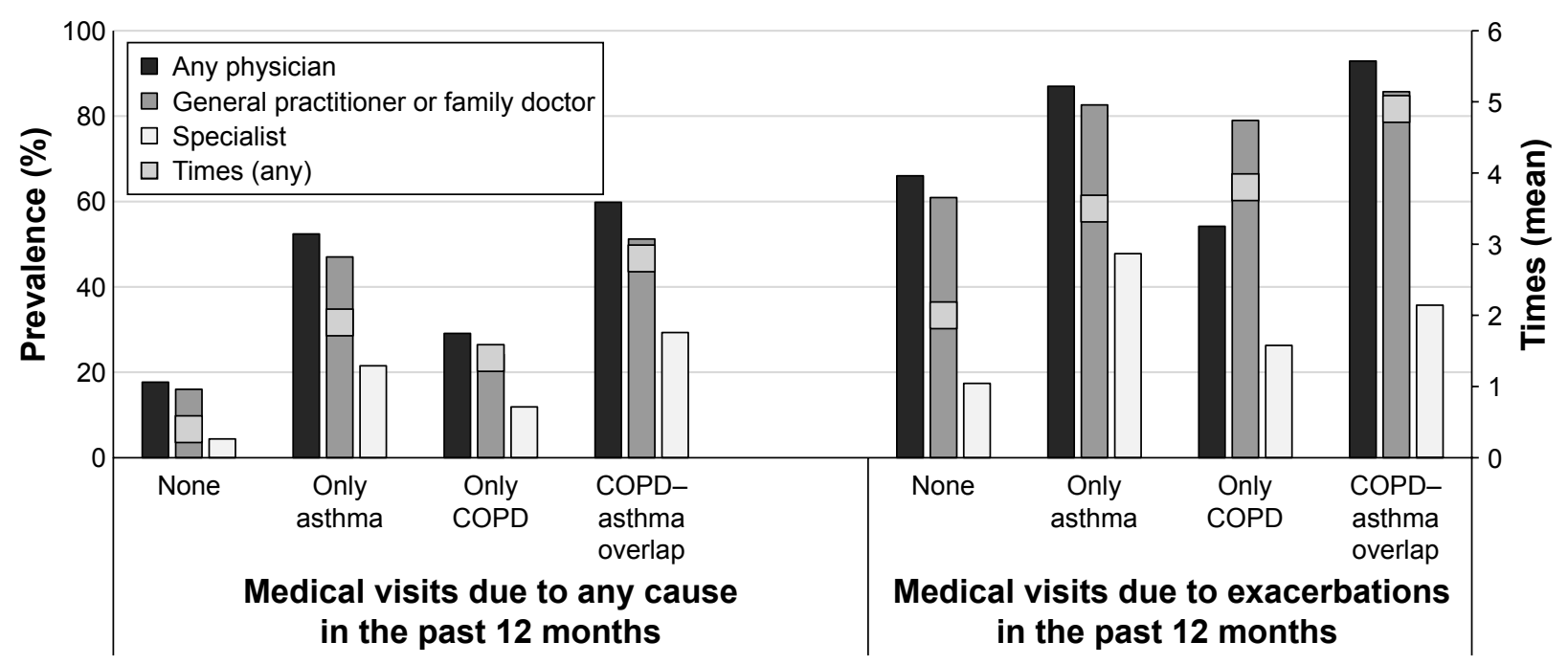

Figure 4 Prevalence of medical visits (to general practitioner/family doctor, specialist, or any physician) due to any cause or exacerbation in the last year in patients with asthma-COPD overlap (post-bronchodilator $\mathrm{FEV} / \mathrm{FVC}<0.70$ plus asthma prior medical diagnosis), only COPD (post-bronchodilator FEV /FVC $<0.70$ ), only asthma (prior medical diagnosis), or without these conditions.

Abbreviations: $\mathrm{FEV}_{1}$, forced expiratory volume in I second; FVC, forced vital capacity.

without this condition, while this was 1.9 times higher for those with only asthma and 1.4 times higher for those with only COPD. Similarly, the number of visits to any doctor due to an exacerbation also appears to be higher in the asthmaCOPD overlap group (4.9 times higher than those without these conditions) than the only asthma (3.5 times higher) and only COPD (3.8 times higher) groups (Figure 4).

\section{Discussion}

The principal findings of this primary care study in a population at risk for COPD (tobacco or biomass smoke exposure) regarding the prevalence of a general medical visit or due to an exacerbation in outpatients with COPD, asthma, or asthma-COPD overlap were as follows: first, the prevalence of any medical visit in the last 12 months in the entire PUMA population was higher in females, younger patients, those with respiratory symptoms, those with increased exposure to biomass smoke, a history of exacerbations in the past year, asthma (defined by reversibility plus wheezing) or COPD (post-bronchodilator $\mathrm{FEV}_{1} / \mathrm{FVC}<0.70$ ), and less schooling. The number of medical visits progressively increases as the severity of dyspnea and airway obstruction worsens. Second, the presence of COPD, asthma, and asthma-COPD overlap increases the prevalence of medical visits, with the highest number of visits to any doctor in the last year in the asthmaCOPD overlap group. Third, exacerbations double the number of medical visits in the last year for patients with COPD, asthma, and asthma-COPD overlap.

Data from a population-based study indicated an important gender difference in the expression of COPD symptoms. ${ }^{29}$ Female gender was a major factor explaining dyspnea and physical activity limitation in the entire study population, as well as in COPD population. Among the subjects with COPD, $10.2 \%$ of females and $5.8 \%$ of males reported ever having had an exacerbation. ${ }^{29}$ These findings may help explain the higher prevalence of any medical visit in females of the PUMA population. A possible explanation of the higher GP visits among the younger patients could be related to the younger age and the higher number of visits to any doctor found in asthmatics compared with COPD patients (asthma 1.9 times, COPD 1.4 times; Figure 4).

The Continuing to Confront COPD International Patient Survey by Foo et al assessed the direct and indirect costs of COPD (based on self-reported physician diagnosis) across 12 countries. ${ }^{17}$ This cross-sectional, population-based study represents one of the most broad assessments of overall COPD costs to date, and the analysis of direct costs was based on COPD exacerbations (treated and those requiring emergency department visits and/or hospitalization), health care professional contact, and COPD medication. With regard to COPD-related health care resource use, patients from all the studied countries (except Japan and Brazil) reported more frequent contact with GPs than with specialists. The number of contacts with GPs in the last year ranged from 2.6 in Spain to 8.3 in the UK, whereas specialist visits in the last year ranged from 1.6 in Russia to 5.1 in Japan. ${ }^{17}$ GP visits substantially contributed to the direct costs in countries such as Mexico (30\%), Japan (28\%), and the UK (26\%), while specialist visits contributed to at least one-quarter of the direct costs in Japan (28\%), the UK (26\%), and the USA (26\%). In addition, the 
authors found that annual societal costs were higher in patients with increased burden of COPD (symptoms, health status, and more severe disease) and higher comorbidities. ${ }^{17}$

Some studies have assessed the cost of COPD management in primary care patients, evaluating the use of health care resources and the contribution of medical visits to these costs. ${ }^{15,30,31}$ Punekar et al reported that the cost of COPD management in the UK primary care setting progressively increased with the number of moderate-to-severe exacerbations, with the health care costs being attributable to GP interactions. ${ }^{15}$ The results also showed that total costs and the various components increased with worsening levels of dyspnea and airflow obstruction, regardless of the exacerbation frequency. ${ }^{15}$ de Miguel Diez et al reported in patients with COPD that the total annual cost was associated with the number of medical visits (primary care physician, pneumologist, and emergency room) and hospital admissions. ${ }^{30}$

In the present study, the prevalence of medical visits was higher in patients with COPD compared with those without COPD, and exacerbations doubled the number of medical visits in the last year. We also found that the prevalence of any medical visit increased with dyspnea and airway obstruction severity. Our results are consistent with those reported in larger studies regarding the use of health care resources ${ }^{15,17,31}$ and support the impact of exacerbations, dyspnea, and airway obstruction severity on the increased use of health care resources in COPD patients. These results may be explained in part by the findings of a population-based study from Latin America region that analyzed the factors that influence exacerbation frequency in the COPD patients. ${ }^{32}$ The proportion of subjects with an exacerbation significantly increased by GOLD stage, from $4.2 \%$ among subjects with stage 1 disease to $28.9 \%$ among those with stages 3 and 4 disease. The results of the multivariate analysis showed that dyspnea, prior asthma diagnosis, use of any respiratory therapy, and more severe obstruction (GOLD stages 3 and 4 vs GOLD stage 1) were the main factors associated with having an exacerbation in the past year. ${ }^{32}$ It is important to highlight that in the PLATINO study, as in the PUMA population, the highest proportion $(>55 \%)$ of patients with COPD were categorized as mild to moderate, helping this to support the findings of previous exacerbations as a predictor of medical visits in a less severe COPD population. ${ }^{32,33}$ Although the design of the PUMA study does not allow assessment of the costs involved in patient management, it is possible to infer that the greater number of medical visits in COPD patients, particularly in those with exacerbations, is likely to have a major impact on the direct costs involved in outpatient management.
Other studies have assessed asthma- and asthma-COPD overlap-related health care resource use and costs..$^{12,34-36}$ Data from two studies included in a systematic review reported physician visits or office-based visits to be the largest expense of asthma-related direct costs, accounting for 55\%-58\% of direct costs. ${ }^{12}$ However, Bedouch et al reported that asthma patients' physician visits accounted for a lower proportion of the total costs $(15.7 \%),{ }^{34}$ while others have found that patients with asthma had significantly higher inpatient admissions, emergency department visits, outpatient visits, and physician office visits compared with those without asthma. ${ }^{35,36}$ In addition, patients with moderate/severe persistent asthma who experienced exacerbations had higher total and asthmarelated health care costs than those without exacerbations. ${ }^{23}$

A retrospective analysis of health care utilization and costs showed that patients with asthma-COPD overlap had nearly double the health care costs compared with only asthma patients. ${ }^{37}$ Similarly, it has been reported that both medical utilization and costs were higher in patients with asthma-COPD overlap than in those with COPD. ${ }^{38}$

Our results are consistent with those reported previously ${ }^{35,36}$ showing that asthma patients, independent of the definition used, have higher physician visits compared with those without asthma, as well as a higher number of visits in those patients experiencing exacerbations. These findings are consistent with others, ${ }^{37,38}$ showing that the number of visits to any doctor in the last year was higher in the asthmaCOPD overlap group than in those with only COPD or only asthma.

This study has some limitations that should be highlighted. We acknowledge that the findings from this study cannot be extrapolated to all Latin American countries as the study was conducted only in four countries; this was the result of limited resources within the countries and also the availability of centers to participate. Nevertheless, the study procedure used was the most sensible given the operational possibilities in each country. To avoid selection bias in the PUMA study, centers were selected based on available lists of primary care physicians and the study subjects were those who visited a center spontaneously. PUMA was a transversal study and so was only designed to evaluate the characteristics of the patients and did not involve any follow-up; we did not assess any pathophysiological link among COPD, asthma, and asthma-COPD overlap groups or a pathway that could help explain the findings. Another limitation of the study was that patients were asked to remember exacerbations and medical visits. Failure to recall information correctly may have influenced the results. 


\section{Conclusion}

The results of the present study indicate that the presence of COPD, asthma, and asthma-COPD overlap patients in the PUMA population increases the prevalence of medical visits and, therefore, also increases health care resource utilization. In addition, exacerbations double the number of medical visits in COPD, asthma, and asthma-COPD overlap patients. Attempts to reduce the use of health care resources and the direct costs involved in the management of these diseases in the primary care setting require interventions or the development of strategies aimed at preventing exacerbations, such as the implementation of smoking cessation and selfmanagement programs, improving adherence to treatment, training patients on the correct use of inhaled therapy, and increased availability of pharmacotherapy.

\section{Acknowledgment}

Editorial support was provided by Ian Wright, of Wright Medical Communications Ltd, and funded by AstraZeneca.

\section{Author contributions}

MMO is the guarantor of the content of the manuscript, including the data and analysis. All authors contributed to the study concept, design, acquisition of data, analysis, and interpretation of data. MMO took the lead role in writing the manuscript, while all authors provided critical revision of the manuscript and read and approved the final version.

\section{Disclosure}

This observational study was funded by AstraZeneca Latin America. AstraZeneca had no input into the study design, analysis and interpretation of the results.

FS is in full-time employment with AstraZeneca Latin America. The other authors report no conflicts of interest in this work.

\section{References}

1. Menezes AM, Perez-Padilla R, Jardim J, et al. Chronic obstructive pulmonary disease in five Latin American cities (the PLATINO study): a prevalence study. Lancet. 2005;366(9500):1875-1881.

2. Mannino DM, Buist AS. Global burden of COPD: risk factors, prevalence, and future trends. Lancet. 2007;370(9589):765-773

3. Buist AS, McBurnie MA, Vollmer WM, et al. International variation in the prevalence of COPD (the BOLD study): a population-based prevalence study. Lancet. 2007;370(9589):741-750.

4. Lopez-Campos JL, Ruiz-Ramos M, Soriano JB. Mortality trends in chronic obstructive pulmonary disease in Europe, 1994-2010: a join point regression analysis. Lancet Respir Med. 2014;2(1):54-62.

5. Rycroft CE, Heyes A, Lanza L, Becker K. Epidemiology of chronic obstructive pulmonary disease: a literature review. Int J Chron Obstruct Pulmon Dis. 2012;7(7):457-494.
6. Menezes AM, Pérez-Padilla R, Wehrmeister FC, et al. FEV1 is a better predictor of mortality than FVC: the PLATINO cohort study. PLoS One. 2014;9(10):e109732.

7. To T, Stanojevic S, Moores G, et al. Global asthma prevalence in adults: findings from the cross-sectional world health survey. BMC Public Health. 2012;12:204.

8. Global Burden of Disease Study 2013. Global, regional, and national age-sex specific all-cause and cause-specific mortality for 240 causes of death, 1990-2013: a systematic analysis for the Global Burden of Disease Study 2013. GBD 2013 Mortality and Causes of Death Collaborators. Lancet. 2015;385(9963):117-171.

9. Burney P, Jarvis D, Perez-Padilla R. The global burden of chronic respiratory disease in adults. Int J Tuberc Lung Dis. 2015;19(1):10-20.

10. Chapman KR, Mannino DM, Soriano JB, et al. Epidemiology and costs of chronic obstructive pulmonary disease. Eur Respir J. 2006;27(1): 188-207.

11. Braman SS. The global burden of asthma. Chest. 2006;130(Suppl 1): 4S-12S.

12. Bahadori K, Doyle-Waters MM, Marra C, et al. Economic burden of asthma: a systematic review. BMC Pulm Med. 2009;9:24.

13. Montes de Oca M, Halbert RJ, Talamo C, et al. Paid employment in subjects with and without chronic obstructive pulmonary disease in five Latin American cities: the PLATINO study. Int J Tuberc Lung Dis. 2011;15(9):1259-1264.

14. Wacker ME, Jörres RA, Schulz H, et al. Direct and indirect costs of COPD and its comorbidities: results from the German COSYCONET study. Respir Med. 2016;111(2):39-46.

15. Punekar YS, Shukla A, Müllerova H. COPD management costs according to the frequency of COPD exacerbations in UK primary care. Int $J$ Chron Obstruct Pulmon Dis. 2014;9(1):65-73.

16. Patel JG, Nagar S, Dalal AA. Indirect costs in chronic obstructive pulmonary disease: a review of the economic burden on employers and individuals in the United States. Int J Chron Obstruct Pulmon Dis. 2014;9(3):289-300.

17. Foo J, Landis SH, Maskell J, et al. Continuing to confront COPD international patient survey: economic impact of COPD in 12 countries. PLoS One. 2016;11(4):e0152618.

18. Jahnz-Rozyk K, Targowski T, From S. Costs of exacerbations of chronic obstructive pulmonary disease in primary and secondary care in 2007 - results of multicenter Polish study. Pol Merkur Lekarski. 2009; 26(153):208-214. Polish.

19. Nielsen R, Johannessen A, Benediktsdottir B, et al. Present and future costs of COPD in Iceland and Norway: results from the BOLD study. Eur Respir J. 2009;34(4):850-857.

20. Ornek T, Tor M, Altin R, et al. Clinical factors affecting the direct cost of patients hospitalized with acute exacerbation of chronic obstructive pulmonary disease. Int J Med Sci. 2012;9(4):285-290.

21. Pasquale MK, Sun SX, Song F, Hartnett HJ, Stemkowski SA. Impact of exacerbations on health care cost and resource utilization in chronic obstructive pulmonary disease patients with chronic bronchitis from a predominantly Medicare population. Int J Chron Obstruct Pulmon Dis. 2012;7(11):757-764.

22. Miravitlles M, Murio C, Guerrero T, Gisbert R. Costs of chronic bronchitis and COPD: a 1-year follow-up study. Chest. 2003;123(3):784-791.

23. Ivanova JI, Bergman R, Birnbaum HG, Colice GL, Silverman RA, McLaurin K. Effect of asthma exacerbations on health care costs among asthmatic patients with moderate and severe persistent asthma. J Allergy Clin Immunol. 2012;129(5):1229-1235.

24. López Varela MV, Montes de Oca M, Rey A, Alejandro Casas A, Stirbulov R, Di Boscio V. Development of a simple screening tool for opportunistic COPD case finding in primary care in Latin America: the PUMA study. Respirology. 2016;21(7):1227-1234.

25. Casas Herrera A, Montes de Oca M, López Varela MV, Aguirre C, Schiavi E, Jardim JR. COPD underdiagnosis and misdiagnosis in a highrisk primary care population in four Latin American countries. A key to enhance disease diagnosis: the PUMA study. PLoS One. 2016;11(4): e0152266. 
26. Schiavi E, Stirbulov R, Hernández Vecino R, Mercurio S, Di Boscio V. COPD screening in primary care in four Latin American countries: methodology of the PUMA study. Arch Bronconeumol. 2014;50(11):469-474.

27. Montes de Oca M, Lopez Varela MV, Jardim J, Stirvulov R, Surmont F. Bronchodilator treatment for COPD in primary care of four Latin America countries: the multinational, cross-sectional, non-interventional PUMA study. Pulm Pharmacol Ther. 2016;38(1):10-16.

28. Vestbo J, Hurd SS, Agusti AG, et al. Global strategy for the diagnosis, management, and prevention of chronic obstructive pulmonary disease: GOLD executive summary. Am J Respir Crit Care Med. 2013; 187(4):347-365.

29. Lopez Varela MV, Montes de Oca M, Halbert RJ, et al. Sex-related differences in COPD in five Latin American cities: the PLATINO study. Eur Respir J. 2010;36(5):1034-1041.

30. de Miguel Diez J, Carrasco Garrido P, García Carballo M, et al. Determinants and predictors of the cost of COPD in primary care: a Spanish perspective. Int J Chron Obstruct Pulmon Dis. 2008;3(4):701-712.

31. Müllerová H, Lu C, Li H, Tabberer M. Prevalence and burden of breathlessness in patients with chronic obstructive pulmonary disease managed in primary care. PLoS One. 2014;9(1):e85540.

32. de Oca MM, Tálamo C, Halbert RJ, et al. Frequency of self-reported COPD exacerbation and airflow obstruction in five Latin American cities: the Proyecto Latinoamericano de Investigacion en Obstruccion Pulmonar (PLATINO) study. Chest. 2009;136(1):71-78.
33. Montes de Oca M, López Varela MV, Laucho-Contreras ME, et al. Classification of COPD patients according to ALAT and GOLD staging systems using PUMA study data. Arch Bronconeumol. 2016 (in press).

34. Bedouch P, Sadatsafavi M, Marra CA, FitzGerald JM, Lynd LD. Trends in asthma-related direct medical costs from 2002 to 2007 in British Columbia, Canada: a population based-cohort study. PLoS One. 2012; 7(12):e50949.

35. Shenolikar R, Song X, Anderson JA, Chu BC, Cantrell CR. Costs of asthma among US working adults. Am J Manag Care. 2011;17(6):409-416.

36. Sullivan PW, Ghushchyan VH, Slejko JF, Belozeroff V, Globe DR, Lin SL. The burden of adult asthma in the United States: evidence from the Medical Expenditure Panel Survey. J Allergy Clin Immunol. 2011; 127(2):363-369.

37. Gerhardsson de Verdier M, Andersson M, Kern DM, Zhou S, Tunceli O Asthma and chronic obstructive pulmonary disease overlap syndrome: doubled costs compared with patients with asthma alone. Value Health. 2015;18(6):759-766.

38. Rhee CK, Yoon HK, Yoo KH, et al. Medical utilization and cost in patients with overlap syndrome of chronic obstructive pulmonary disease and asthma. COPD. 2014;11(2):163-170.
International Journal of COPD

\section{Publish your work in this journal}

The International Journal of COPD is an international, peer-reviewed journal of therapeutics and pharmacology focusing on concise rapid reporting of clinical studies and reviews in COPD. Special focus is given to the pathophysiological processes underlying the disease, intervention programs, patient focused education, and self management protocols.

\section{Dovepress}

This journal is indexed on PubMed Central, MedLine and CAS. The manuscript management system is completely online and includes a very quick and fair peer-review system, which is all easy to use. Visit http://www.dovepress.com/testimonials.php to read real quotes from published authors. 